\title{
A CASE OF LISTERIOSIS OF THE NEWBORN
}

\author{
Jean M. Scott ANd A. Henderson \\ Research Department, Glasgow Royal Maternity Hospital, \\ Glasgow \\ Plates VIII-X
}

SINCE the description of " granulomatosis infantiseptica" by Reiss, Potel and Krebs (1951) in Halle, Germany, and the publication of evidence associating this disease with infection by Listeria monocytogenes (for references see Seeliger, 1958), we have sought unsuccessfully for similar cases over a period of nearly $10 \mathrm{yr}$. This disease appears to be less frequent in Britain than in Germany because few cases have been reported from other centres in this country; in America, on the other hand, the incidence of the disease seems to be rising. Driscoll, Gorbach and Feldman (1962) think that this may be due to improved methods of identification, but our experience does not support this view.

The case reported here, which is the only one we have seen in approximately 3000 necropsies, is one of the few in which the organism was isolated from both mother and baby. The gross pathological features were atypical and gave no indication of the nature of the infection.

\section{CASE HISTORY}

The mother, a 28-yr-old woman with one previous uneventful pregnancy, reported to the outpatient clinic at 24 weeks' gestation with complaints of nausea, disturbance of vision and a heavy brown vaginal discharge. The Kahn test for syphilis gave a negative result; the blood haemoglobin level was $10.2 \mathrm{~g}$ per cent. Apart from the administration of iron no treatment was given, and her symptoms disappeared as her general health improved. The pregnancy advanced normally. Seven days before the expected date she was delivered spontaneously of a female child weighing $2.26 \mathrm{~kg}$. The baby was limp and pale, and made no attempt to breathe; resuscitation with intermittent positive pressure from a Bird respirator was begun. At $10 \mathrm{~min}$. the Apgar was still 1 (heart beat). Respirations commenced $12 \mathrm{~min}$. after birth, when tracheal intubation was performed, but were weak. The baby's condition deteriorated and death occurred at the age of $1 \mathrm{hr} 50 \mathrm{~min}$.

\section{NECROPSY}

The external appearances were those of a slightly premature female child (crown-heel $46 \mathrm{~cm}$, crown-rump $32 \mathrm{~cm}$ ), showing patchy cyanosis. The cord was attached and clean.

The main pathological changes were in the lungs (weight $34 \mathrm{~g}$ and $27 \mathrm{~g}$ ), which were heavy, solid, bulky and haemorrhagic. Slight patchy aeration was present in all lobes, and portions of each floated in formol-saline. There was a

Received 15 Jan. 1968; accepted 14 Feb. 1968.

J. MED. MICROBIOL.-VOL. 1 (1968)

97

G 
fibrinous pleurisy on the left side; $5-10 \mathrm{ml}$ of straw-coloured fluid were found in each pleural cavity. The airways were clear.

At the lower end of the oesophagus there was thick, yellowish pus. Both mediastinal and mesenteric lymph-nodes were congested and the former were enlarged to about three times normal size. No other features of note were recorded.

The placenta had been placed in a sealed plastic bag immediately after delivery and was examined some $20 \mathrm{hr}$ later. It weighed $475 \mathrm{~g}$. A foul smell, not normally present, was noted when the bag was opened. The cord and foetal surface were already discoloured. At the lower edge a peculiar soft haemorrhagic area had spread up between two lobes; adjacent to this there was a small old white infarct $(2 \mathrm{~cm}$ in diameter). One other small, white infarct was seen elsewhere in the placenta.

\section{HISTOLOGY}

The lungs. Many small granulomata, mainly peribronchial and perivascular, are present throughout both lungs (fig. 1). Surrounding these are areas of intense congestion and sometimes also of haemorrhage. Occasionally, there is ulceration of a bronchus (fig. 2). Inflammatory exudate, mainly polymorphonuclear in type, is present in many of the medium- and small-sized bronchi, and there is also a patchy pneumonia. Tiny granulomata of microscopic size are scattered all over the pleura (fig. 3), which is oedematous and shows a diffuse polymorph and mononuclear infiltrate. Spread to the pleura is either direct from the lung itself or along the fibrous septa, which are very oedematous. Over the left lung there is marked thickening of the pleura with deposition of fibrin. The vessels of both lungs are filled with polymorphs and lymphocytes, and the peribronchial lymphatic tissue is prominent.

There is a marked increase in the cellular content of the mediastinal lymphnodes, which also show intense congestion. Many of the capsular vessels are packed with large mononuclear cells together with some lymphocytes and occasional polymorphs. Lymphopoiesis is active in the node, and many of the centres of lymphopoietic activity seem to be around congested blood vessels. No germ centres are seen. Larger cells with more abundant basophilic cytoplasm and nuclei with finer chromatin network can be seen between the clusters of lymphocytes. These resemble the " monocytoid cells" described by Conway $(1938,1939)$ and others (Gray and Killinger, 1966) in experimental animals into which Listeria monocytogenes had been injected intravenously. In places, sheets or clumps of these large, pale cells can be seen, and here the cells tend to develop an epithelioid appearance (figs. 4 and 5). Occasional macrophages and eosinophils are also scattered throughout the nodes, but polymorphs are not prominent. No necrotic areas are seen. The normal pattern of the node is distorted by the intense cellular proliferation, and it is impossible to distinguish cortex from medulla.

Compared with the mediastinal nodes, the mesenteric nodes show little change. Lymphopoiesis is not prominent, but an occasional gland shows some " sinus catarrh" (fig. 6). 
In the liver, scattered foci of erythropoiesis are present, and some of the red cell precursors show signs of nuclear pyknosis and fragmentation. Adjacent parenchymal cells occasionally show degenerative changes, mainly chromatolysis.

In the spleen there is some increased activity in the lymphatic tissue round the arterial tree. Some of the lymphocytes at the periphery show monocytoid change. The red pulp is congested. Reactive changes are present in the thymus, in which the cortex shows the typical "starry sky" pattern. Unlike those in the lymph-nodes, the changes in the thymus are non-specific and similar to those found in other infective processes.

Apart from asphyxial haemorrhage, the brain and meninges show no abnormality.

Granulomata were not found elsewhere.

The placenta. Random blocks from cord, membranes and placenta were examined, together with blocks from the area of white infarction and haemorrhagic necrosis at the lower edge of the placenta. Apart from congestion of the villi, the placenta generally shows little pathological change. At the lower edge, however, many microscopic granulomata are present in relation to the area of necrosis which has spread upwards into the decidual septum to involve adjacent placenta (fig. 7). Here the villi are caught up in a fibrin-like mass. Early signs of necrosis can be seen in the trophoblast of the enmeshed villi and in some there is already proliferation of Hofbauer cells. Polymorphs, mononuclear cells and proliferating chorionic cells are present in the fibrin mass and in the decidual layer that forms the floor of the lesion. To one side lies the old white infarct with its villi well hyalinised. Obviously it antedates the more acute inflammatory process alongside, but it may have provided a portal of entry for the infection.

On the surface of the amnion, numerous colonies of Gram-positive bacilli can be seen (fig. 8). These have probably arisen from post-mortem growth during storage, but at the lower edge there is an inflammatory reaction in the amnion and chorion. No inflammation can be seen elsewhere in the chorion and no vasculitis or inflammation of the cord is present. Sections from the main lesion on the decidual surface show numerous Gram-positive bacilli (fig. 9). Grampositive bacilli are also present in sections of the lungs, and in an ulcer in the oesophagus (fig. 10). A few small clumps are present in the sinusoids of the liver. One vessel in the brain also contains a small clump, but neither here nor in the liver is there any sign of cellular reaction.

\section{BACTERIOLOGICAL FINDINGS}

Fluid from the pleural cavity and pus from the oesophagus of the baby were plated on blood agar; colonies appeared within $24 \mathrm{hr}$. A swab was collected from an erosion on the cervix of the mother $6 \mathrm{wk}$ after delivery. It was plated on horse-blood agar containing potassium tellurite and left at room temperature until colonies developed.

A motile, non-sporing, Gram-positive bacillus, which was aerobic and facultatively anaerobic, was isolated from all specimens. It grew on nutrient 
agar, and colonies on blood agar were surrounded by a narrow zone of haemolysis. Flagellation was peritrichous, and motility was more active at $22^{\circ} \mathrm{C}$ than at $37^{\circ} \mathrm{C}$.

The organism was catalase-positive and oxidase-negative, and did not form indole; it was positive in the methyl red and Voges-Proskauer tests. Nitrate was not reduced to nitrite, and gelatin was not liquefied. Tests for the production of hydrogen sulphide and for urease activity were negative.

Acid was formed within 5 days in peptone-water containing the following substances ( 1 per cent. w/v): arabinose (one strain only), xylose, glucose, laevulose, sucrose, maltose, lactose, trehalose, glycerol, mannitol and salicin. No acid was formed in 7 days in rhamnose, mannose, galactose, raffinose, dextrin, inulin, adonitol, dulcitol, erythritol, sorbitol, inositol and amygdalin. Aesculin was hydrolysed in 1 day.

Strains from both baby and mother belonged to serotype $4 \mathrm{~b}$ of $L$. monocytogenes.

\section{Discussion}

Although L. monocytogenes appears to be ubiquitous in its distribution (see Gray and Killinger, 1966), there are inexplicable differences between countries in the incidence of human listeriosis, particularly in the perinatal period. At the University Women's Clinic in Leipzig the disease accounts for 0.15 per cent. of the total perinatal mortality; at Halle the figure is even higher ( 2 per cent.), and on occasion in some areas in Germany the disease has reached almost epidemic proportions (Breuning and Fritzsche, 1954). Reports of cases have since been accumulating rapidly from other parts of the world (Gray and Killinger), but Barber and Okubadejo (1965) could find only five neonatal cases in the British literature in addition to the one that they described. Beck, O'Brien and Mackenzie (1966) found one case after a 4-yr search. Apart from this, brief reports of two other cases have appeared (Coleman, 1965; Jellard and Churcher, 1965).

It has been suggested that a latent reservoir of infection may exist in women in countries where the incidence is high. Indeed, it has been shown that persistence of the organism in the genital tract may lead to habitual abortion. In Germany, Seeliger (1958) found that among women who had given birth to infants infected with Listeria, 16 per cent. had previously aborted or produced stillbirths. From Israel, Rappaport et al. (1960) reported the isolation of Listeria from 25 out of 34 women who had a history of repeated abortion. In this country, however, MacNaughton (1962) failed to isolate Listeria from the vagina of 78 cases of abortion in Aberdeen, and in the Grimsby area Robertson (1966) examined 136 placentas from stillbirths, abortions, neonatal deaths and premature deliveries and failed to grow Listeria. We ourselves have examined vaginal swabs from 100 cases of postpartum pyrexia, 100 of vaginal discharge and 30 of abortion in Glasgow women and failed to isolate the organism. Britain is not, however, exceptional in this respect, because negative reports have also been made from Israel (Rabau and David, 1963) and America (Lawler et al., 1964; Quarles and Pitman, 1966). 
Infection in the mother may also be associated with infection in the father. In our case, the patient was unmarried and we were unable to examine the father, but in Israel, Toaff, Krochik and Rabinovitz (1962) examined the husbands of 60 women who had had an abortion and in three instances isolated $L$. monocytogenes from the semen, which also showed, among other changes, dyspermia and a reduced sperm count. In this country there is at present no information about the incidence of infection in the male, but it certainly seems that genital infection in the female is uncommon.

When infection occurs, it may attack the foetus by one of the following three routes.

(1) It may spread directly across the placenta from the maternal blood. Generally, the mother gives a history of some systemic illness beforehand. Gray and Killinger reviewed published work, and found that the mother frequently complains of fever, chills, sore throat, dizziness, pains in the back and diarrhoea, shortly before or around delivery, and that this illness may be followed by diminution or loss of foetal movements, premature delivery or stillbirth. In Barber and Okubadejo's case a blood culture taken from a 21-yrold Ghanaian woman living in Britain at the 28th wk of pregnancy yielded $L$. monocytogenes, and after a premature labour the $2 \frac{1}{2}-\mathrm{lb}$. infant died within a few hours with the features of "granulomatosis infantiseptica". L. monocytogenes was isolated at necropsy from the cerebrospinal fluid.

(2) The infection may follow aspiration or swallowing of infected liquor. Johnston et al. (1955) in Canada stressed the significance of this route, and in their two cases isolated the organism successfully for the first time from both mother and baby. On each occasion, L. monocytogenes was isolated from the mother's vagina. The first baby lived the longer and the lesions were more advanced. Cultures of the blood and the cerebrospinal fluid yielded L. monocytogenes. Death occurred at $36 \mathrm{hr}$, and at necropsy " granulomatosis infantiseptica" was found. The second case resembled ours more closely. Death occurred $2 \mathrm{hr}$ after delivery, and the pathological features were those of bronchopneumonia with a few abscesses in the adrenal glands. Pus was found on the surface of the gastric mucosa, and this was regarded as further evidence implicating the liquor. In our case, pus was found in the oesophagus.

It seems that the liquor may become infected with $L$. monocytogenes even when the membranes are intact. This happened in our case, in which the membranes ruptured only $10 \mathrm{~min}$. before delivery. Dungal (1961) records an instance in Iceland in which a woman sought a therapeutic abortion because her earlier children had died in infancy of central nervous system disease. The foetus was received with intact membranes and L. monocytogenes was isolated from the liquor. During a later pregnancy, oxytetracycline was administered for 7 days in each month from the 3rd mth onwards; the child was normal at birth and was well 10 mth later.

(3) Finally, the infant may be infected at delivery from a lesion in the cervix or vagina. This group, in which L. monocytogenes has remained localised and has not invaded the gestation sac, may be regarded as differing only in degree from (2). However, these infections may be regarded as a separate group, 
because the majority present as meningeal listeriosis later in the neonatal period or early in infancy. In a few instances only can the original source in the mother be identified. According to Gray and Killinger, such cases represent 40 per cent. of all human listerial meningitis reported in the USA. We ourselves have had experience of one such case. It is therefore important to detect and treat chronic listerial infection in pregnant women, though they may have no complaint. Hood (1961) described four women from whom Listeria was isolated by blood culture; they were subsequently delivered of healthy infants after treatment with antibiotics.

Apart from the cases already cited, there have not been many reports of isolation of the organism from mothers of affected infants. Wiener (1957) isolated Listeria from the blood and cerebrospinal fluid of an infant and from its mother's vagina. Welshimer (1963, cited by Banner et al., 1964) isolated it in the 3rd mth of pregnancy from the blood culture of a woman who aborted subsequently. Ray and Wedgwood (1964) isolated the organism from an infant's blood and cerebrospinal fluid, and from the maternal endometrium; both mother and child were cured. Most of these reports are fairly recent and of American origin. This would support the prediction of Driscoll et al. (1962) that, with improved methods of identification, the source of infection would more often be found in the mother, at least in some parts of the world.

With regard to the pathology of the present case, the following points deserve mention. Firstly, the case presented as one of a bronchopneumonia with bilateral pleurisy and effusion. Gray and Killinger state that this form of listeriosis is rare. Suspicion was aroused because the pathological changes in the lung were not in keeping with a history of rupture of the membranes only $10 \mathrm{~min}$. before delivery. Microscopy of the lung might have aroused suspicion of listeriosis on account of the peribronchial lesions and granulomata. The lymph-node changes were also unusual. Normally, in the newborn, the nodes are poorly developed and occasional clumps of rather loosely packed lymphocytes and an occasional reticulum cell make up the rather thin cortex. The medulla is also poorly developed and consists of loose connective tissue with a diffuse scattering of lymphocytes and frequent small blood vessels. In infections, some lymphoid hyperplasia is usually present, and there are signs of sinus catarrh and marked congestion, but the monocytoid reaction noted here was exceptional. Reference to experimental work in animals (Conway, 1938, 1939), where Listeria had been injected intravenously, suggests that these changes take at least $24 \mathrm{hr}$ to develop. In our case, where infection was by aspiration, the process would probably take longer. Nevertheless, death occurred relatively early in this baby, though the infection remained localised to the lungs, and before any systemic lesions were detected.

The changes in the placenta are also of interest. In the past this organ does not seem to have been studied in any great detail, but recently, Driscoll et al. made the diagnosis of listeriosis from placental examination. They saw areas of haemorrhagic necrosis throughout the placenta, and concluded that the foetus had been infected by the transplacental route, for only mild inflammatory change was noted in the membranes and no necrosis was seen. In our case, the 
A CASE OF LISTERIOSIS OF THE NEWBORN

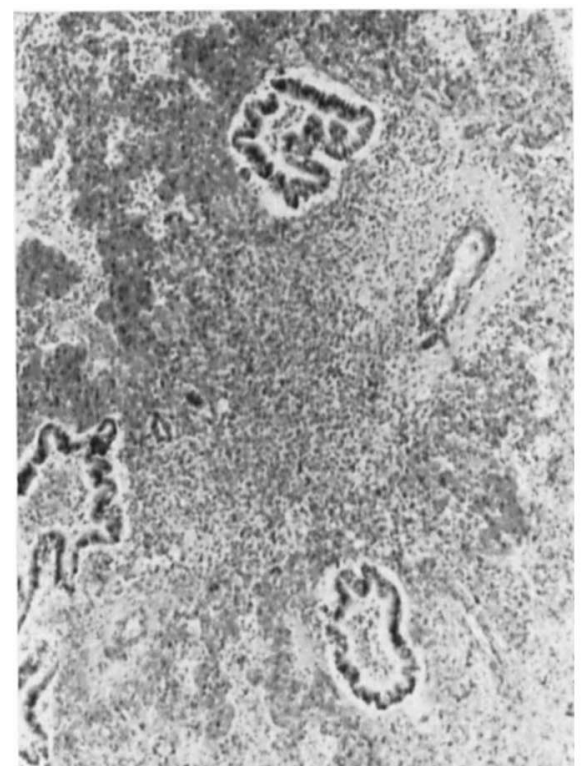

Fig. 1.-Lung. Fusion of peribronchial granulomata, developing pneumonia. Haematoxylin and eosin. $\times 65$.

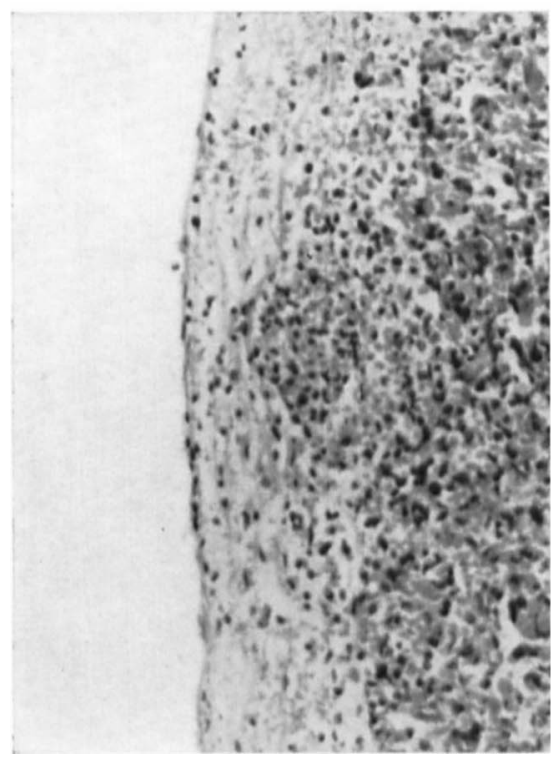

FIG. 3.-Lung. Early granulomatous lesion in pleura. HE. $\times 150$.

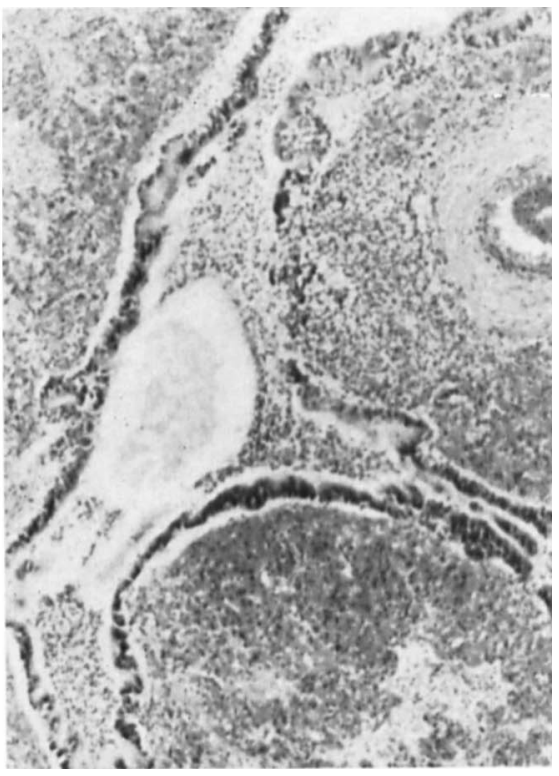

FIG. 2.--Lung. Granuloma rupturing into bronchus. HE. $\times 65$.

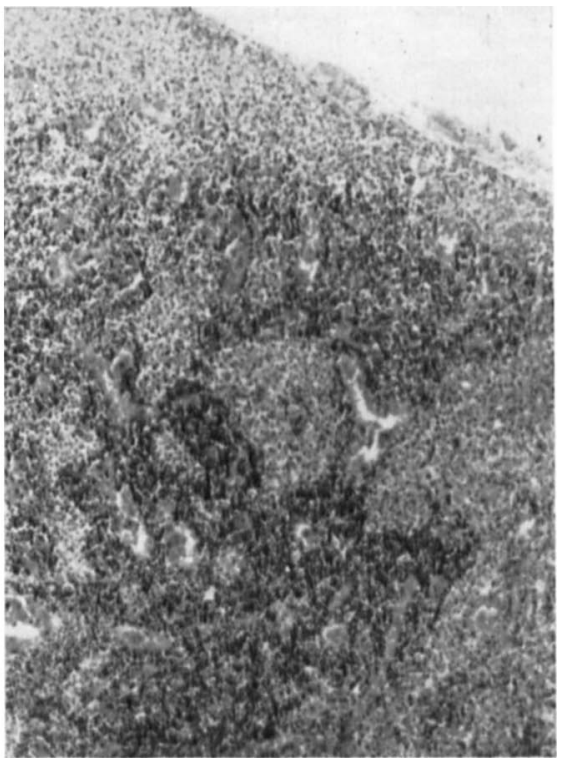

FIG. 4.-Mediastinal lymph-nodes with sheets of cells showing monocytoid changes. HE. $\times 65$. 
A CASE OF LISTERIOSIS OF THE NEWBORN

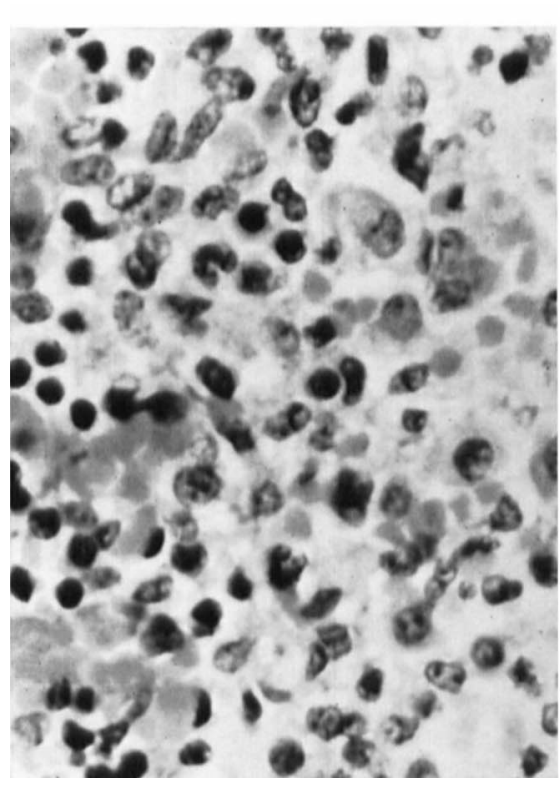

FIG. 5.-Higher-power view of monocytoid cells. HE. $\times 600$.

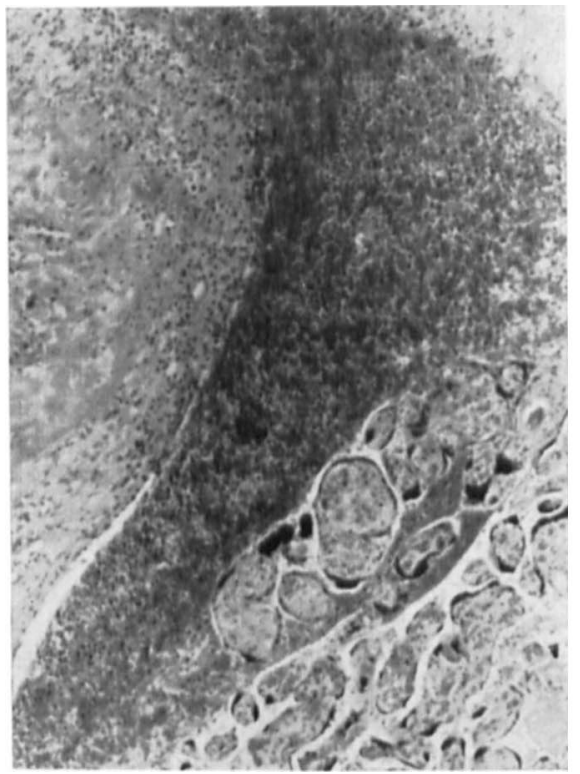

FIG. 7.--Placenta. Inflammatory process spreading out from decidual septum on the left. HE. $\times 65$.

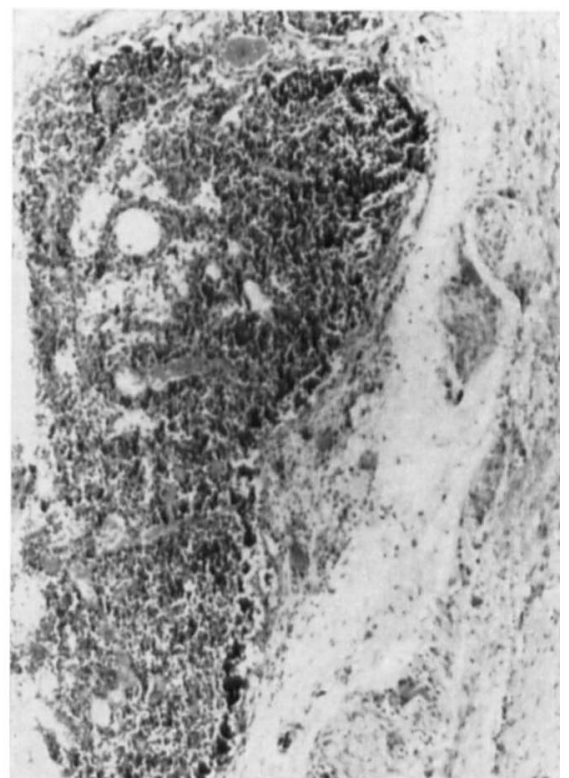

FIG. 6.-Mesenteric node. Some sinus catarrh. HE. $\times 65$.

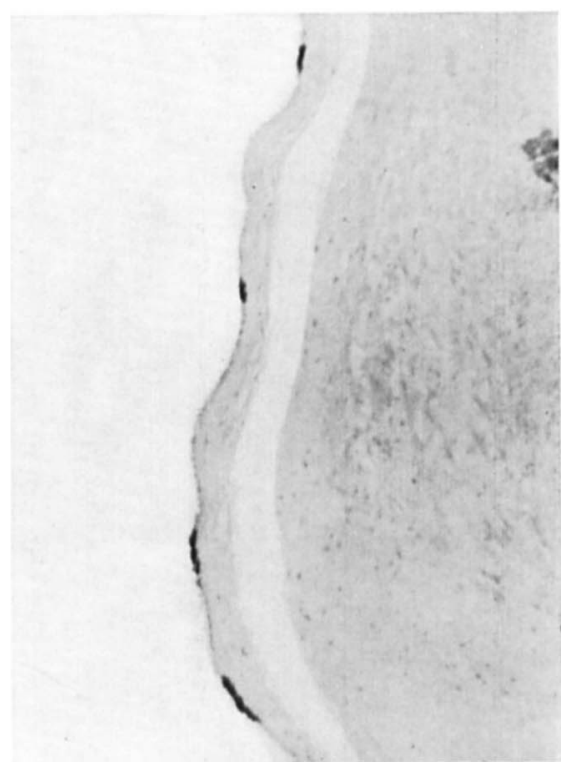

FIG. 8.-Amnion. Colonies of Gram-positive bacilli, Eosin Gram-Weigert. $\times 65$. 
A CASE OF LiSteriosis OF THE NEWBORN

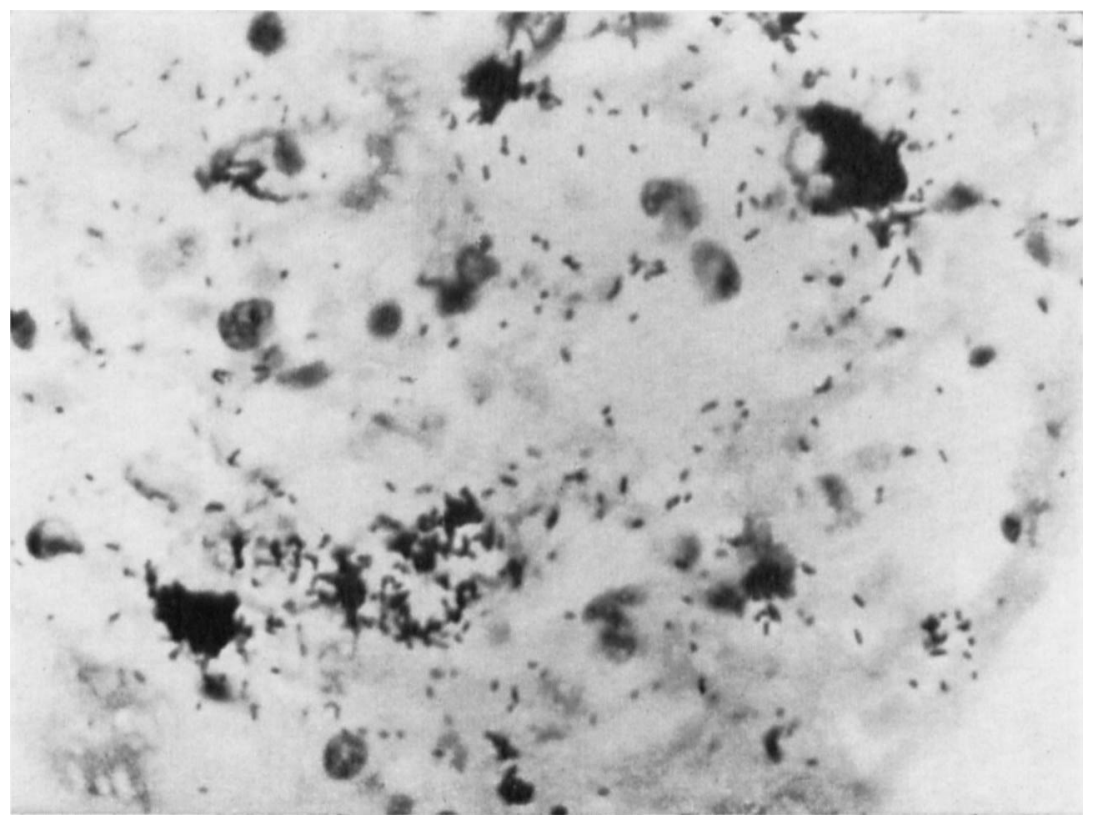

FIG. 9.-Placenta. Gram-positive bacilli in decidua. EGW. $\times 900$.

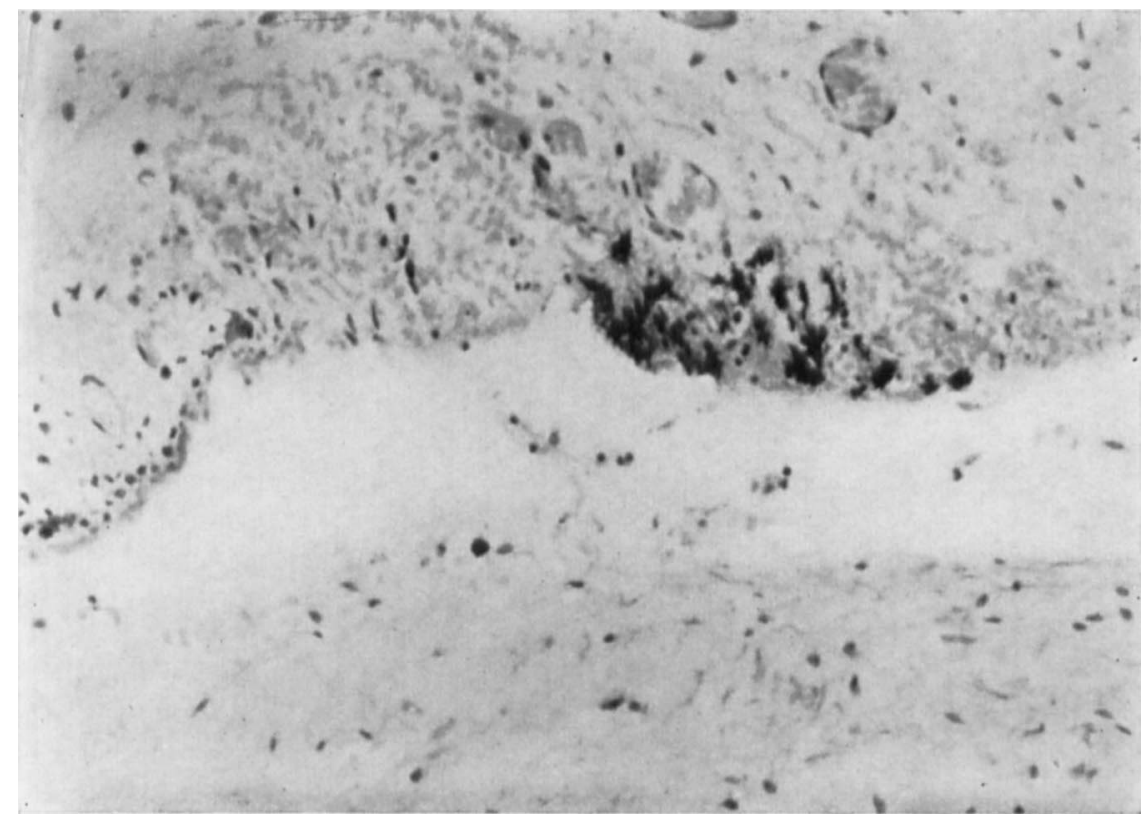

FIG. 10. - Oesophageal ulceration showing growth of organisms. EGW. $\times 225$. 
lesion was still localised to the lower edge of the placenta, but otherwise the changes resembled those described by Driscoll et al. Elsewhere the membranes showed even less change, but, like these authors, we were impressed by the number and size of the colonies of Gram-positive bacilli growing on the amnion. Admittedly, much of this might be post-mortem growth, but it is surprising that we should not see the organisms growing in a similar fashion in other sorts of placentitis when the collection and storage of the placenta before examination are the same. It may be that the ability of $L$. monocytogenes to spread, survive and multiply on the surface of the amnion is in some way related to its power of invading the amniotic cavity without rupture of the membranes.

The circumstances of the present case suggest that the source of infection was infected liquor, as there was evidence of both aspiration and deglutition of infected material. However, it seems likely that the mother was harbouring Listeria in her cervix, for at the post-natal visit a small erosion was found there, and it was from this erosion that we were able to grow the organism.

\section{SUMMARY}

An atypical case of perinatal infection with Listeria monocytogenes is described, in which the main pathological feature was a congenital bronchopneumonia.

The membranes were intact until just before delivery, and death occurred within $2 \mathrm{hr}$ of birth, but well-established changes were present in the lungs, placenta and mediastinal lymph-nodes, which showed a "monocytoid" reaction. The organism was isolated from both mother and baby and was found to belong to serotype $4 \mathrm{~b}$.

We wish to thank Professor H. P. R. Seeliger, who kindly typed the organisms, and Mr R. Risk for his technical assistance with the flagellar stains; and also Professor D. F. Anderson and Dr John McLaurin for their cooperation. We are grateful to Dr A. D. T. Govan, Director of the Research Department, and to Mr Andrew Fraser for help with the photographs.

\section{REFERENCES}

Banner, E. A., Johnson, T. R., Onstad, G. R., Weed, L. A., and Sayre, G. P.

Barber, MARY, AND OKubadeJo, O. A. .

Beck, A., O’Brien, P. K., AND MACKENZIE, V. F.

Breuning, M., and Fritzsche, F. -

Coleman, P. N. . . . . . .

Conway, Eleanor A. . $\quad$. . . .

Driscoll, 'SHIRley G., Gorbach, A., AND FELDMAN, D.

Dungal, N.

Gray, M. L., AND Killinger, A. H.

HOOD, M. . . . . . .

Jellard, G. H., AND ChuRCher, Gillian

R.
1964. Proc. Staff Meet. Mayo Clin., 39, 919.

1965. Br. Med.J., 2, 735.

1966. J. Clin. Path., 19, 567.

1954. Geburtsh. Frauenheilk., 14, 1113.

1965. Br. Med. J., 2, 878.

1938. Archs Path., 25, 200.

1939. J. Infect. Dis., 64, 217.

1962. Obstet. Gynec., N.Y., 20, 216.

1961. Lancet, 2, 513.

1966. Bact. Rev., 30, 309.

1961. Pediatrics, 26, 390.

1965. Br. Med. J., 2, 878. 
Johnston, W. H., Morton, S. A., 1955. Canad. Med. Assoc. J., 73, 402. WONG, M. H., AND ROY, T. E.

LAWLeR, F. C., WoOD, W. S., KING, 1964. Amer. J. Obstet. Gynec., 89, 915. SYLVIA, AND METZGER, W. I. MACNAUGHTON, M. C.

1962. Lancet, $2,484$.

Quarles, J. M., AND Pitman, B. . . 1966. J. Bact., 91, 2112.

RABAU, E., AND DAVID, A. . . 1963. J. Obstet. Gynaec. Br. Commonw., 70, 481.

RAPPAPORT, F., RABINOVITZ, M., TOAFF, 1960. Lancet, 1, 1273.

R., AND KROCHIK, N.

RAY, C. G., AND Wedgwood, R. J. $\quad$. 1964. Pediatrics, 34, 378.

ReISs, H. J., POTEL, J., AND KREBS, A. - 1951. Klin. Wschr., 29, 29.

ROBERTSON, J. S.
SEELIGER, H. P. R.

SEELIGER, H. P. R. $\quad$. $\quad$. $\quad$. $\quad$. 1958. Beitr. Hyg. Epidemiol., 8.

ToAfF, R., KROCHIK, N., AND RabiNo- 1962. Lancet, $2,482$. VITZ, $M$.

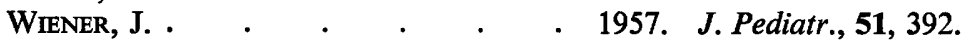

